\title{
SEDIMENTARY SEQUENCE ANALYSIS ON THE NORTHERN MARGIN OF THE ORDOS BASIN BASED ON MARKOV PROCESS
}

\author{
WANG, J. ${ }^{1,3}-$ LU, L. J. ${ }^{1 *}-$ DING, R. ${ }^{2}$ \\ ${ }^{I}$ Digital Geoscience of Institution, Jilin University, Jilin University, Changchun 130000, China \\ ${ }^{2}$ Institute of Special Education, Changchun University, Changchun 130000, China \\ ${ }^{3}$ School of Electronic Information Engineering, Changchun University, Changchun, 130000, \\ China \\ *Corresponding author \\ e-mail: lulj@jlu.edu.cn
}

(Received $7^{\text {th }}$ Jun 2019; accepted $10^{\text {th }}$ Oct 2019)

\begin{abstract}
Uranium is of great importance to China's nuclear energy and national defense. As a clean energy, the nuclear energy helps to adjust and optimize the energy structure, improve the ecoenvironment, and reduce the $\mathrm{CO}_{2}$ and $\mathrm{S}$ emissions, paving the way to sustainable development and ecological civilization. The sandstone-type uranium deposit, one of the four types of uranium deposits for industrial use, is an important supplier in China. This type of uranium deposit mainly exists in sandstone basins. And the basin is a complex space of different sedimentary strata and facies. Hence, basin analysis is an essential approach to determine the distribution and variation law of uranium resources. This paper mainly studies the sandstone-type uranium deposits on the northern margin of the Ordos Basin, China. Firstly, the author collected typical data of the geological features on the basin, and sorted data gathered from typical boreholes. Next, the Markov process model was adopted to analyze the sedimentary sequence and evolution in the basin. Finally, the relationship was clarified between the spatial distribution of uranium resources and the stratum evolution of the sedimentary basin.
\end{abstract}

Keywords: uranium, spatial distribution, sandstone-type, deposit, strata

\section{Introduction}

Uranium resources is a very important strategic material in China's nuclear energy strategic objectives and national defense construction. It is also an important guarantee for China's nuclear energy development. The national medium and long-term development plan for nuclear power (2011-2020) states that carbon dioxide emissions per unit of GDP will drop by $40 \%$ to $45 \%$ by 2020 compared with 2005 , and the proportion of non-fossil energy in primary energy consumption will reach around $15 \%$. The proportion of nuclear energy in most developed countries in the world has exceeded $20 \%$, while that in China is less than $2 \%$. In order to ensure the long-term stable supply and strategic reserve of uranium resources in China, it is necessary to have enough natural uranium supply and reserve resources as guarantee (Jin et al., 2015). Therefore, it is of great significance to adjust and optimize China's energy structure, improve the ecological environment, and reduce $\mathrm{CO}_{2}$ and $\mathrm{S}$ emissions.

There are two giant uranium metallogenic belts in the world, one is the giant uranium metallogenic belt running through north and South America, the other is the giant uranium metallogenic belt in Europe and Asia. The sandstone uranium metallogenic belt in northern China is located in the eastern section of the Eurasian uranium metallogenic belt. It indicates that China has superior geological conditions and 
resource potential for uranium mineralization. Sandstone-type uranium deposit has many advantages such as large scale, low cost of in-situ leaching and environmental protection, at present, it has become the main type of ore deposit in the world and the main type of uranium resources in China. Sandstone-type uranium deposit is one of the four major industrial uranium mine types in China. As we know the majority of uranium mine in China is sandstone type deposits, and it plays a very important role in the supply of uranium resources in China. The formation conditions of such a deposit are relatively stable, so it is easy to form large and ultra-large deposits (Liu et al., 1997). Sandstone uranium deposit is a major uranium resource type around the world, it mainly exists in sandstone basins (Adler, 1974), and the basin which are complex formation spaces for different sedimentary strata and facies. As studies indicated sandstone uranium deposits in the north of China is very huge (Wang et al., 2019). Therefore, sedimentary basin analysis has become an important area of the study of the distribution and variation law of uranium resources, and the analysis of ore-bearing space involves the analysis of these dimentary sequence of strata (Zhang and Han, 2008), the sedimentary phase change law, and the localization of redox environment. And now, quantitative analysis and digital simulation of basins have become an important direction and trend for the researches in this field at home and abroad (Brookins, 1976; Cohenour, 1960; Elmasour and Elseed, 2018; Fu et al., 2018; Liu et al., 2006; Liu and Jiao, 2013; Miao and Jiao, 2010; Wyborn et al., 1995).

\section{Materials and methods}

\section{Basic geological conditions of the Ordos Basin}

The Ordos Basin is located in the western part of the North China Plate and is one of the large inland depression sedimentary basins in China (Zhang and Chen, 2010). The basin is rectangular-shaped and spreads from north to south direction, covering an area of about $250,000 \mathrm{~km}^{2}$. It is an important basin containing coal, oil, natural gas, uranium and other resources, as shown in Figure 1.

The Ordos Basin has a two-layer structure. The basement layer consists mainly of metamorphic rocks of the Archaean Eonothem and the Paleoproterozoic Erathem, together with marine facies limestone and clastic sedimentary rocks of the Mesoproterozoic Erathem (Chen and Li, 2003; Chen and Xiang, 2010), the Neoproterozoic Erathem, and the Paleozoic Erathem. The caprock layer is continental facies clastic sedimentary rocks of the Mesozoic Erathem and the Cenozoic Erathem. The Dongsheng sandstone-type uranium deposit is located in the eastern part of the Ordos Basin. The ore-bearing stratum is the gray medium sandstone and medium-coarse sandstone in the lower section of the Middle Jurassic Series Zhiluo Formation, and these sandstones are composite watercourse sands of multi-stage braided river in deeply incised valley under humid climate conditions (Adler et al., 1974). The erosion surface of the sandstone was developed, where in the Middle Jurassic Series Zhiluo Formation in the ore-bearing stratum conformably or disconformably capped on the coal-bearing stratum of the Middle Jurassic Series Yan'an Formation (Miao and Jiao, 2010; Lin et al., 2007). In terms of geotectonic structure, it belongs to the Ikh Juu League uplift zone. In the Early Paleozoic Era, the basin accepted the shallow marine clastic rocks and carbonate sedimentary rocks, and in the Late Paleozoic Era, the marine facies and continental facies deposited stably and alternately. In the Late Triassic Epoch, the inland depression formed, and very thick Mesozoic Erathem fluviatile-lacustrine facies 
clastic rocks deposited, then the later Yanshan movement caused the Upper Jurassic Series and the Upper Cretaceous Series missing from the Mesozoic Erathem. During the development of the basin, paleogeographic conditions such as the climate changed from wet to dry and several regional sediments had been interrupted, had laid a basis for the formation of sandstone-type uranium deposits.

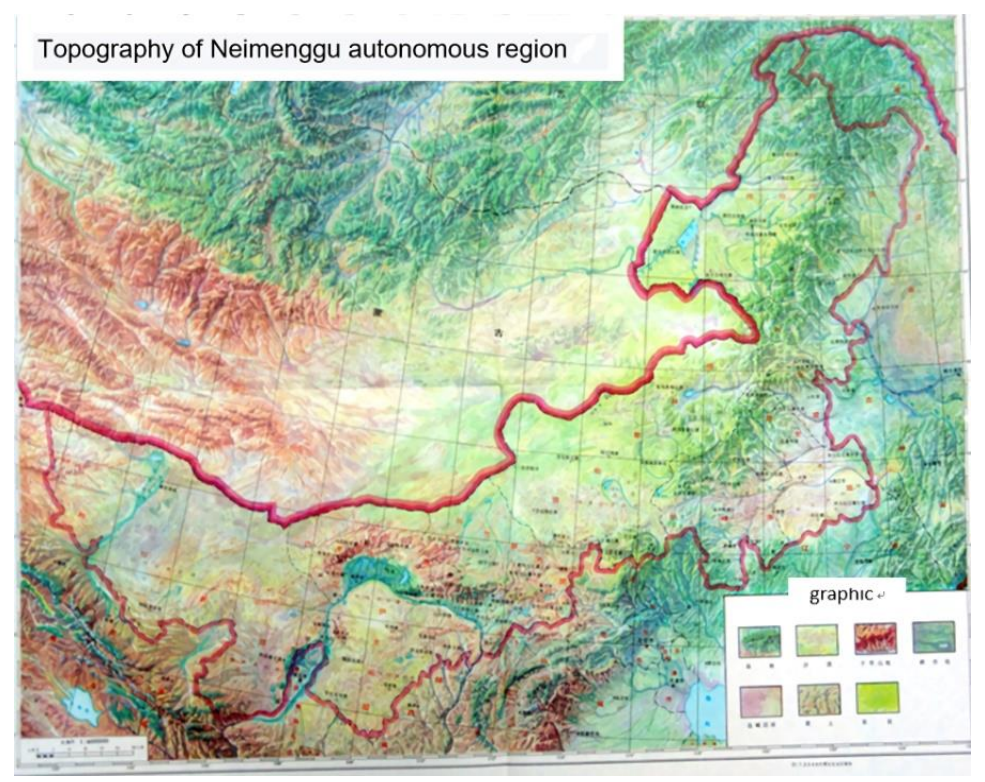

Figure 1. Terrain of the Ordos Basin

\section{Borehole data of the Ordos Basin}

This study collected several dozens of the sandstone uranium samples from the Dongsheng sandstone uranium mine area in the Ordos Basin and from several wells in the Huanglong area. The rock type of the uranium-bearing minerals is mainly variegated grayish-green sandstones of the Middle Jurassic Series Zhiluo Formation, with mediumgrained sand-like structures. Thin section identification results indicate that the sandstones are mainly composed of plagioclase, quartz, muscovite, chlorite and epidote (Chen and Li, 2003), and the cement consists of clay minerals, carbonates and a small part of limonite.

The sampling of sandstone uranium was completed in the 28th Brigade of the Ministry of Nuclear Industry, which is a subordinate unit of the geology and minerals department of the CNNC (China National Nuclear Corporation), it is a deputydepartment level national secondary public institution with 1,500 employees and 6 Grade-A qualification certificates such as the regional geological survey certificate. Since 2000, it has made major breakthroughs in uranium mines and made important contributions to rapidly improving the uranium resources capacity of China.

To ensure the uranium content of the samples, detailed geological and geophysical exploration and cataloging of the newly constructed boreholes was carried out to deepen our macroscopic understanding of the ore-bearing sandstones. The boreholes of the uranium industry were selected as research objects. The surrounding rocks (including gray sandstones and grayish-green sandstones) at different positions around the orebearing stratum, mineralized sandstones and uranium ore samples were collected, and every sample was subject to the radioactivity measurement on the site. The well logging 
borehole samples are shown in Figure 2, and the well logging data are shown in Table 1 and Figure 3.

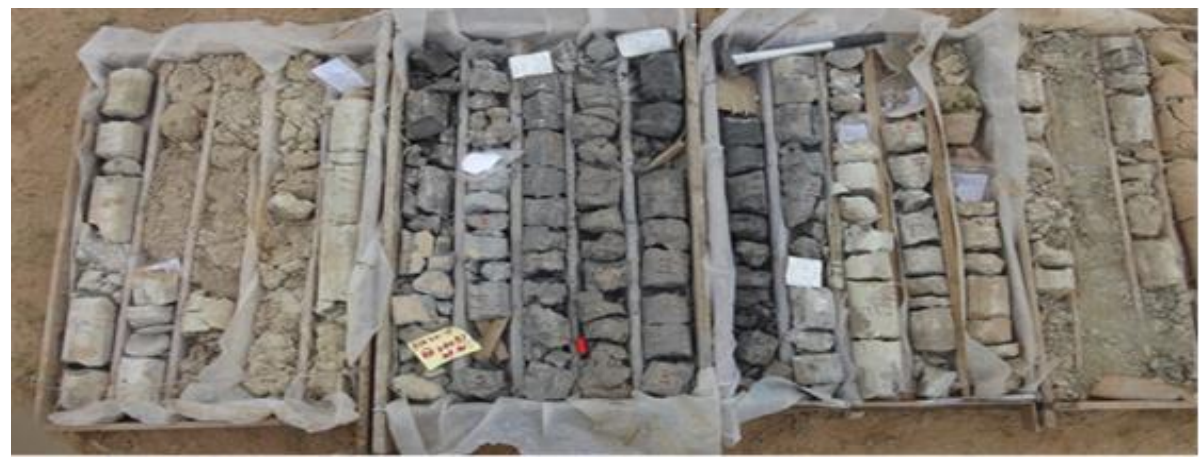

Figure 2. Borehole samples of the Ordos Basin

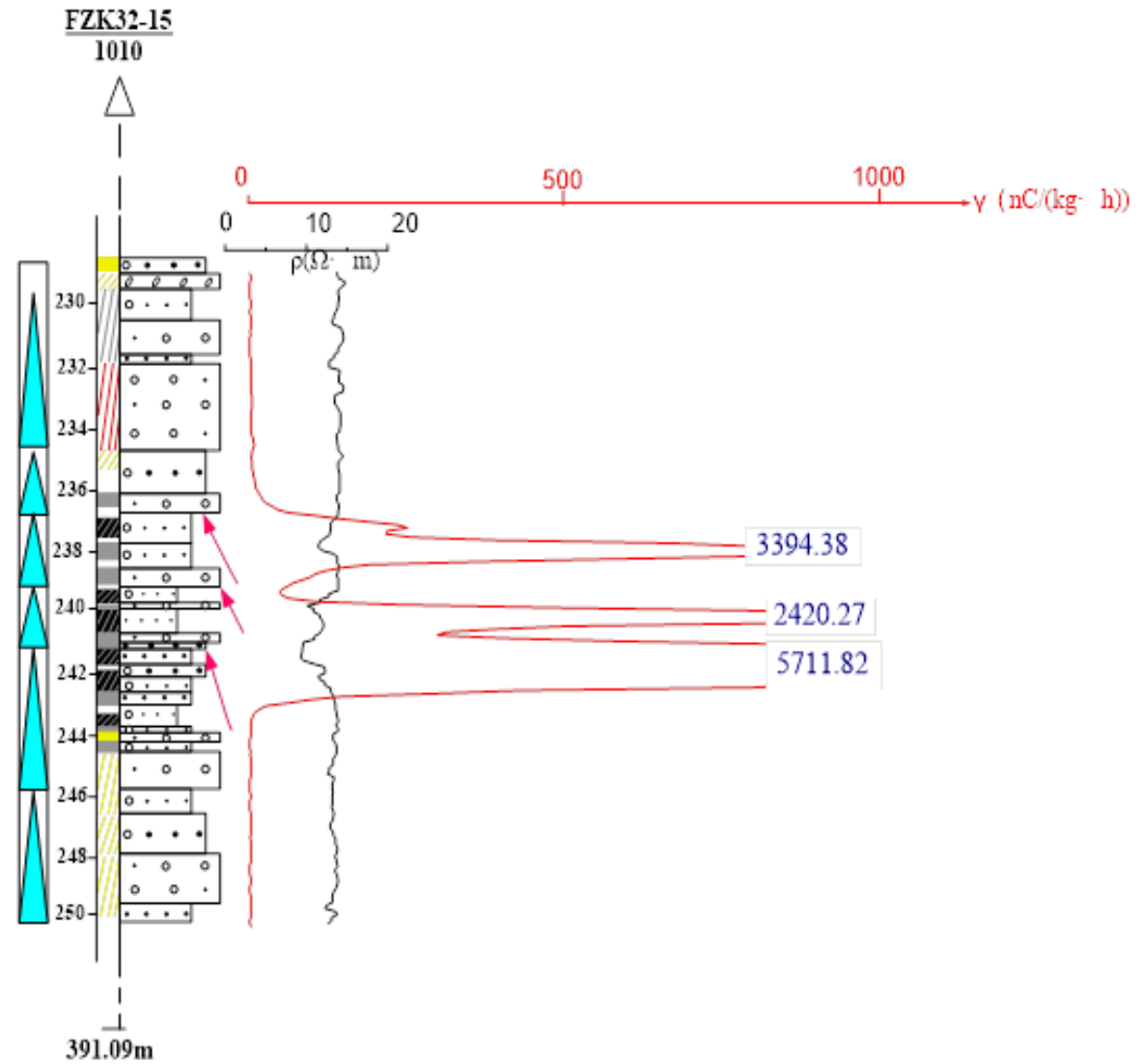

Figure 3. Borehole data of the Ordos Basin

Table 1. Well logging data of the Ordos Basin

\begin{tabular}{c|c|c|c|c}
\hline Well logging & $\begin{array}{c}\text { Burial depth of } \\
\text { the ore block }(\mathbf{m})\end{array}$ & $\begin{array}{c}\text { Thickness } \\
(\mathbf{m})\end{array}$ & $\begin{array}{c}\text { Grade } \\
\mathbf{\%}\end{array}$ & $\begin{array}{c}\text { Uranium content per square } \\
\text { meter }\left(\mathbf{k g} / \mathbf{m}^{\mathbf{2}}\right)\end{array}$ \\
\hline Middle well logging & $236.37-243.27$ & 6.90 & 0.4449 & 65.70 \\
Basic well logging & $236.23-243.03$ & 6.80 & 0.4383 & 63.77 \\
Inspection well logging & $236.23-243.23$ & 7.00 & 0.4162 & 62.34 \\
\hline
\end{tabular}


According to the identified sandstone-type uranium mines and the collected coalfield radioactive well logging data we can know that, the uranium-bearing strata in the northeastern Ordos Basin are mainly the Zhiluo Formation, followed by the Yan'an Formation.

The Yan'an Formation is a set of sedimentary stratum dominated by fluviatilelacustrine delta facies, which are mainly dark-colored sandstones, mudstone and shale interbeds, and stably developed coal seams, containing rich animal and plant fossils and organic matters. Generally (Zhang and Li, 2010), it is composed of two lithologic sections that are tapered upwards; the lower section consists of gray medium-grained and finegrained mingled sandstones and mudstones. The sand body is rich in reducing media such as charcoal and pyrite; nonuniform thickness, the sandstones' cementation matter is mainly the mud, and the consolidation degree is relatively loose; the upper section is dominated by grayish-white medium- or fine-grained sandstones, followed by gray or black mudstones, quartz sandstones are seen locally, and grayish-white kaolinized sandstones are seen at the top, with mud as cementation matter and high degree of consolidation, local sections were altered and became kaolin, which is a unique weathering product when the Yan'an Formation is exposed on the surface. The currently found mineralized uranium is mainly concentrated in this section, as shown in Figure 4.

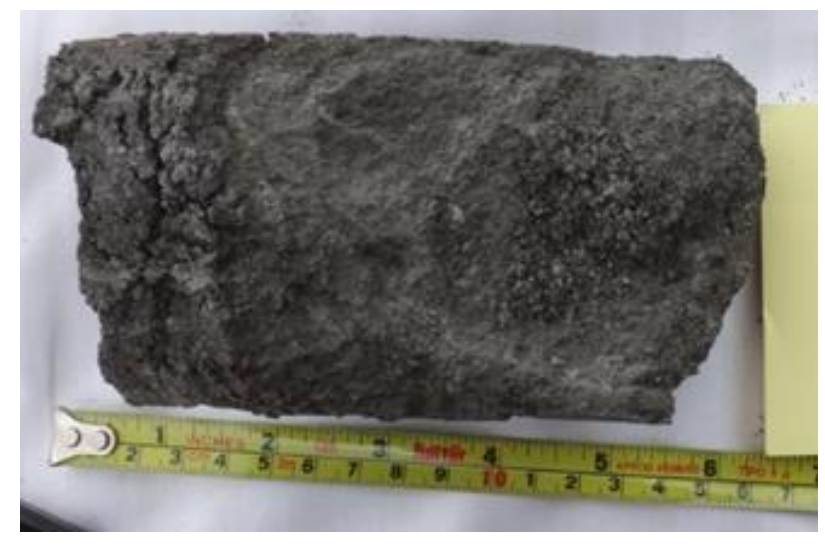

Figure 4. Rock core of the Yan'an Formation

According to the characteristics of well logging curve, lithology, cycle and color, the Zhiluo Formation can be divided into the lower section and the upper section. The lower section of the Zhiluo Formation is stable throughout the whole area, and it is mainly composed of primary gray clastic rocks, and the sand body of fluviatile facies had developed. Figure 5 shows the stratigraphic division and logging response of the Zhiluo Formation.

\section{Markov probability}

If a process is given a "present", then its "future" is independent of its "past", and such a random process is called a Markov process. The Markov chain is a time-discrete, state-discrete Markov process. In a Markov chain, the transfer of system states can be represented by a transition probability matrix, namely $P=\left[P_{i j}\right]$. The elements in the transition matrix are called transition probabilities. The transition matrix has two important properties, that is, all elements are non-negative and the sum of the elements is equal to 1 , namely $P_{i j} \geq 0, \sum P_{i}=1,2,3, \ldots, n$. Therefore, the formula is as follows: 


$$
\left(P_{i j}\right)_{n \times n}=\left[\begin{array}{cccc}
P_{11} & P_{12} & \cdots & P_{1 n} \\
P_{21} & P_{22} & \cdots & P_{2 n} \\
\vdots & \vdots & \ddots & \vdots \\
P_{n 1} & P_{n 2} & \cdots & P_{n n}
\end{array}\right] \Delta P_{j} \sum_{j=1}^{n} P_{i j}=1
$$

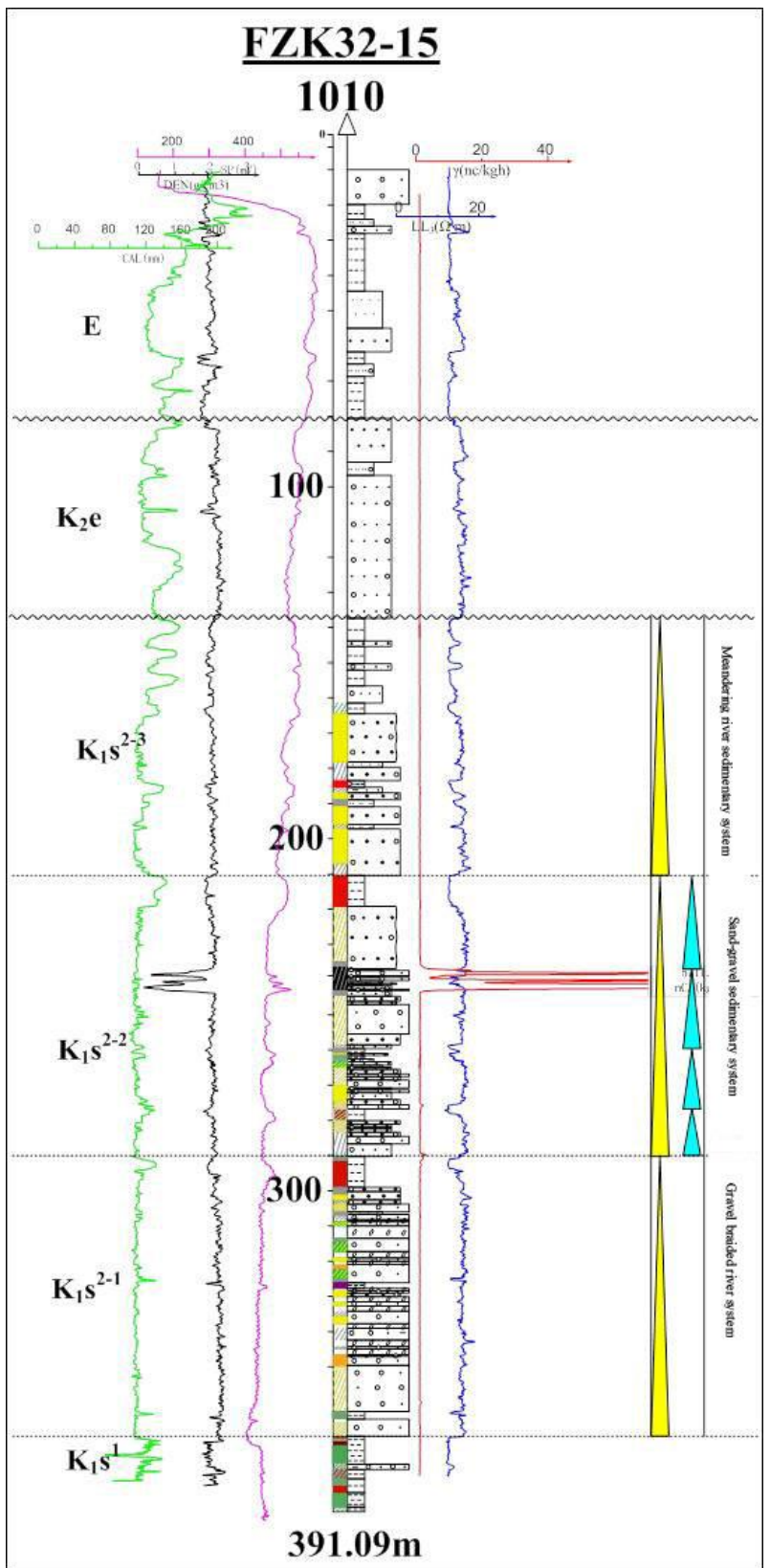

Figure 5. Stratigraphic division and logging response of the Zhiluo Formation

When the system state starts from any fixed state $i$, goes through a transition and reaches the state $\mathrm{j}$, then it will generates states $E_{1}, E_{2}, E_{3}, \cdots, E$, so $P_{i j}$ would constitute a probability matrix, which is a first-order transition probability matrix. Therefore, accordingly, there are also second-order, third-order, and n-order (high-order) transition probability matrices. And high order transition probability matrix can be obtained by matrix multiplication: $P^{(n)}=P^{(1)} \cdot P^{(n-1)}$, and the formula is as follows: 


$$
\left(P_{i j}(k)\right)_{n \times n}=\left[\begin{array}{llll}
P_{11}(k) & P_{12}(k) & \cdots & P_{1 n}(k) \\
P_{21}(k) & P_{22}(k) & \cdots & P_{2 n}(k) \\
\vdots \\
P_{n 1}(k) & P_{n 2}(k) & \cdots & P_{n n}(k)
\end{array}\right] \triangleq P(k)
$$

Therefore, the k-th transition probability matrix is equal to the k-th power of onetime transition, namely:

$$
P(k)=\left(P_{i j}(k)\right)_{n \times n}=P(1)^{k}=\left[\begin{array}{llll}
P_{11} & P_{12} & \cdots & P_{1 n} \\
P_{21} & P_{22} & \cdots & P_{2 n} \\
\vdots & & & \\
P_{n 1} & P_{n 2} & \cdots & P_{n n}
\end{array}\right]^{k}
$$

\section{Markov prediction model}

Assume the system has $\mathrm{n}$ mutually incompatible states, and the initial state vector of the system is:

$$
S(0)=\left[S_{1}(0), S_{2}(0), \cdots, S_{j}(0), \cdots, S_{n}(0)\right]
$$

where, $S_{j}(0)$ is the initial probability that the system is in the state $\mathrm{j}$.

Since after $k$-steps transition the probability that the system is in state $j$ is $S_{j}(\mathrm{k})$, then after $k$-steps transition, the state vector is:

$$
S(k)=\left[S_{1}(k), S_{2}(k), \cdots, S_{j}(k), \cdots, S_{n}(k)\right]
$$

where, $S_{j}(k)$ is the probability that the system is $j$ in a state at the moment k.

Therefore, the Markov prediction model is:

$$
\begin{aligned}
S(k) & =S(k-1) \cdot P=S(k-1)\left[\begin{array}{cccc}
P_{11} & P_{12} & \cdots & P_{1 n} \\
P_{21} & P_{21} & \cdots & P_{2 n} \\
\cdots & \cdots & \cdots & \cdots \\
P_{n 1} & P_{n 2} & \cdots & P_{n n}
\end{array}\right] \\
& =S(0) \cdot P^{k}=S(0) \cdot\left[\begin{array}{cccc}
P_{11} & P_{12} & \cdots & P_{1 n} \\
P_{21} & P_{21} & \cdots & P_{2 n} \\
\cdots & \cdots & \cdots & \cdots \\
P_{n 1} & P_{n 2} & \cdots & P_{n n}
\end{array}\right]
\end{aligned}
$$

The spatial distribution of the basin sediment formation is multicomponent, heterogeneous, periodic and extensive, and the distribution in each stratum layer is regular. The research results show that the distribution of the sedimentary strata in the basin has Markov characteristics. The sedimentary strata have the characteristics of complexity and cyclicity. In the structure of the basin, the uranium-bearing stratum is only one of the sections. If each stratum is regarded as a state, then the probability of the stratum can be represented by the number of times the stratum appears in the entire sedimentary strata, and a Markov probability matrix can be constructed with the probabilities of all strata. Therefore, the Markov process can be used to clarify the 
sequence of the sedimentary process of the strata and even the cyclic or the phase change law, thus establishing a Markov process model for stratum sediment.

According to the collected logging data, part of the borehole data is shown in Figure 6 . The basin stratum sequence can be sorted from bottom to top. According to the borehole data, there were a total of 55 stratum samples, which can be divided into 36 lithologic states after repeated screening, and some lithology states after screening are shown in Table 2.

\section{ZK5-1Borehole integrated histogram}

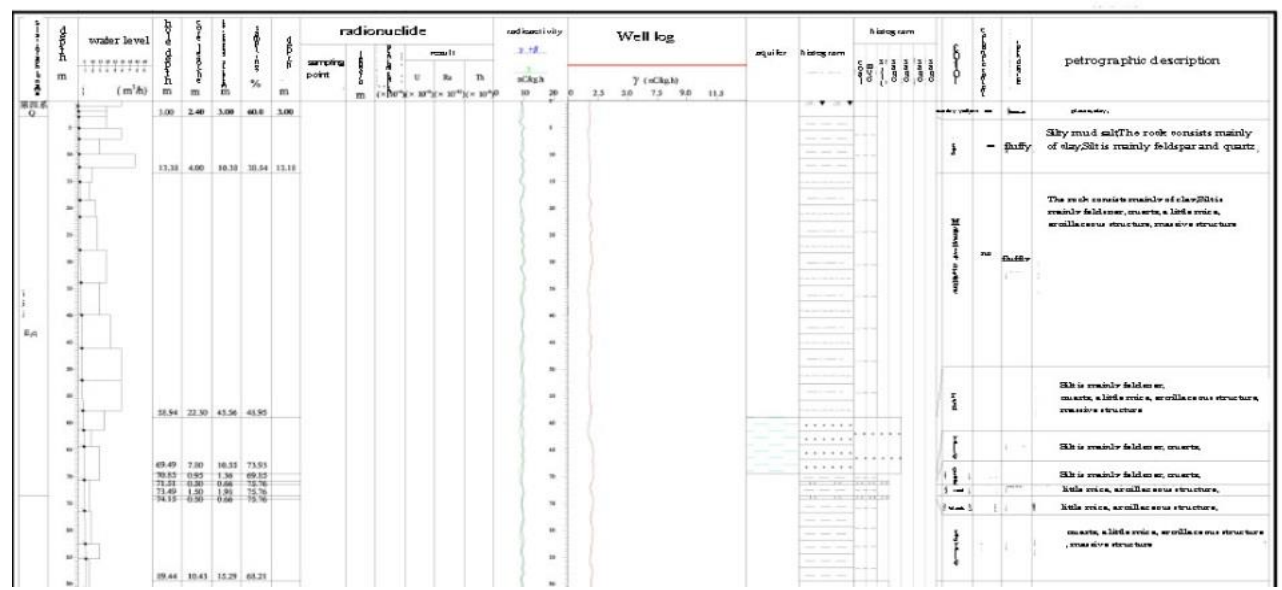

Figure 6. Partial comprehensive histogram of the Ordos Basin

Table 2. Partial lithology states after screening

\begin{tabular}{c|c|c|c|c|c}
\hline Layer & Petrographic description & Type & Layer & Petrographic description & Type \\
\hline 1 & Coarse gravel sandstone (light grayish green) & 1 & 15 & Coarse gravel sandstone (light brown yellow) & 10 \\
2 & Carbonaceous mudstone (grayish black) & 2 & 16 & Silty mudstone (blue gray) & 3 \\
3 & Silty mudstone (blue gray) & 3 & 17 & Coarse gravel sandstone (gray, off-white) & 12 \\
4 & Coarse gravel sandstone (off-white) & 4 & 18 & Oil sand salt (gray, off-white) & 12 \\
5 & Fine gravel salt (off-white) & 5 & 19 & Coarse gravel sandstone (off-white) & 4 \\
6 & Coarse gravel sandstone (off-white) & 6 & 20 & Medium pebbled sandstone (off-white) & 13 \\
7 & Silty mud salt (blue grey) & 3 & 21 & Fine sand salt (off-white) & 5 \\
8 & Carbonaceous mud salt (gray black) & 2 & 22 & Oil sand salt (light brown yellow) & 14 \\
\hline
\end{tabular}

Therefore, the one-step probability matrix of the mutual transition of 36 lithology is calculated by MATLAB:

$$
P_{36}=\left[\begin{array}{cccccccccc}
0 & 1 & 0 & 0 & 0 & 0 & 0 & 0 & \cdots & 0 \\
0 & 0 & 0.33 & 0 & 0 & 0 & 0.33 & 0.33 & \cdots & 0 \\
0 & 0.33 & 0 & 0.33 & 0 & 0 & 0 & 0 & \cdots & 0 \\
0 & 0 & 0 & 0 & 0.25 & 0 & 0 & 0 & \cdots & 0 \\
\vdots & \vdots & \vdots & \vdots & \vdots & \vdots & \vdots & \vdots & \vdots & \vdots \\
0 & 0 & 0 & 0 & 0 & 0 & 0 & 0 & \cdots & 1 \\
0 & 0 & 0 & 0 & 0 & 0 & 0 & 0 & \cdots & 0
\end{array}\right]
$$


The probability of two-time transitions is:

$$
P_{36}{ }^{2}=\left[\begin{array}{cccccccccc}
0 & 0 & 0.33 & 0 & 0 & 0 & 0.33 & 0.33 & \cdots & 0 \\
0 & 0.43 & 0 & 0.27 & 0 & 0 & 0 & 0 & \cdots & 0 \\
0 & 0 & 0.1 & 0 & 0.08 & 0 & 0.1 & 0.1 & \cdots & 0 \\
0 & 0 & 0.25 & 0.25 & 0.12 & 0 & 0 & 0 & \cdots & 0 \\
\vdots & \vdots & \vdots & \vdots & \vdots & \vdots & \vdots & \vdots & \vdots & \vdots \\
0 & 0 & 0 & 0 & 0 & 0 & 0 & 0 & \cdots & 0 \\
0 & 0 & 0 & 0 & 0 & 0 & 0 & 0 & \cdots & 0
\end{array}\right]
$$

According to the modeling process, if the initial state of an event at moment (or period) $\mathrm{K}$ is known, then by using Equation 2 we can obtain its possible variation trend at the first moment (or period) after one-time state transition, as shown in Figure 7. Therefore, through calculation, we can get the probabilities of various possible states after one-time transition, as shown in Figure 8. And so on, we can also obtain the variation trend of the event's two-time state transition at the second moment (or period), as shown in Figure 9. And the prediction of the probability of two-time transition is shown as Figure 10.

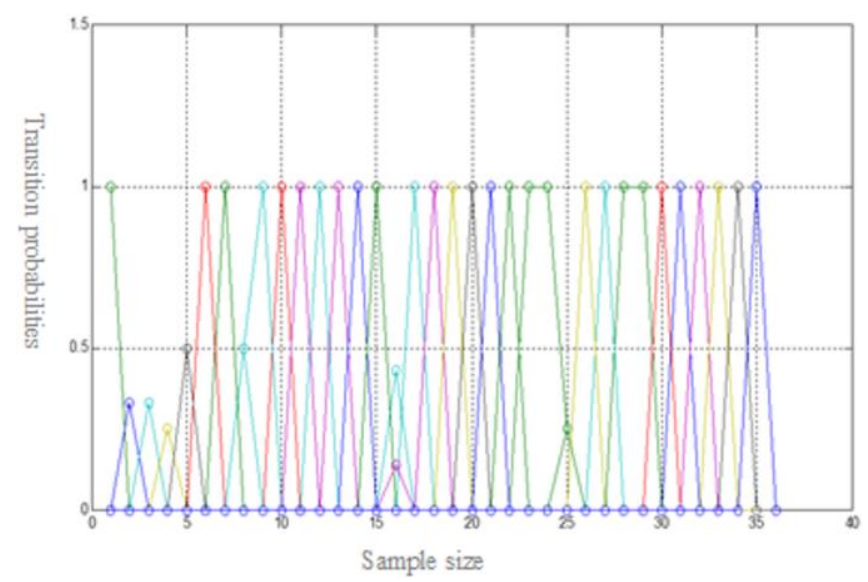

Figure 7. Variation trend of one-time state transition

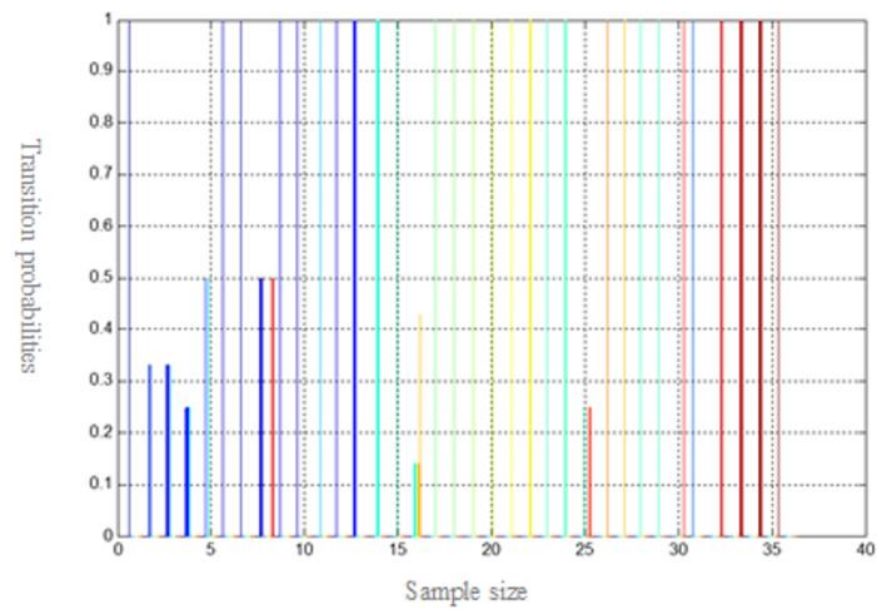

Figure 8. Probability of one-time state transition 


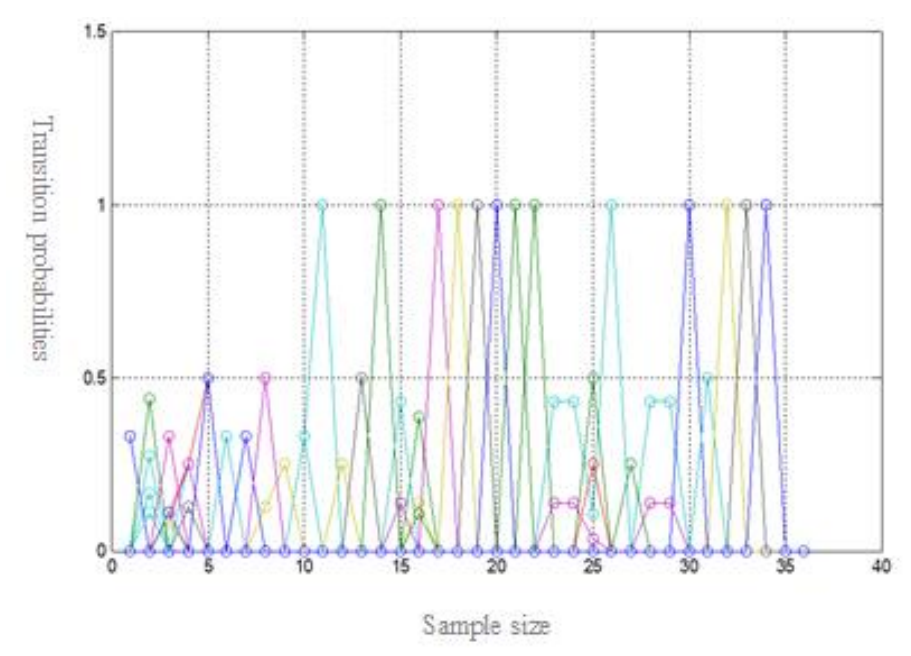

Figure 9. Variation trend of two-time state transition

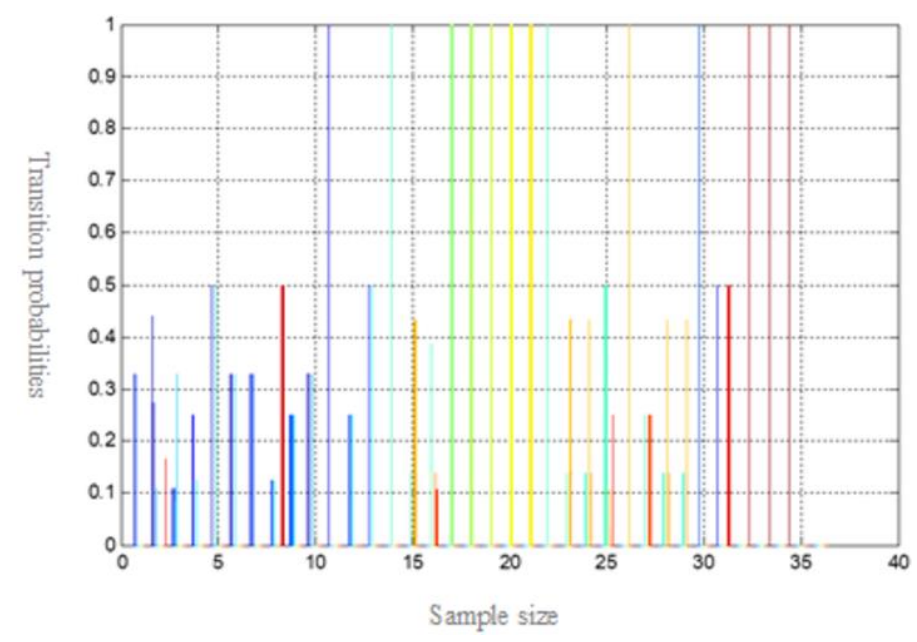

Figure 10. Probability of two-time state transition

\section{Results}

Therefore, through the Markov probability modeling process we can know that, regardless of the one-time transition probability or the two-time transition probability, the transition probability of all lithology does not exceed 1. Color is a simple and direct feature mark of rocks. Color is usually used to describe rocks and distinguish mineral components, and the color change of rock surface is an important basis for obtaining and identifying rock and mineral information. By looking up the lithology transition states we can see that, in the one-time transition probabilities, the probability of transferring from carbonaceous mudstone (grayish black) to silty mudstone (blue-gray) is $33 \%$, the probability of transferring from carbonaceous mudstone (grayish black) to coal (black) is $33 \%$, the probability of transferring from carbonaceous mudstone (grayish black) to mudstone (dark grayish green) is $33 \%$. The probability of transferring from silty mudstone (blue-gray) to carbonaceous mudstone (grayish black) is $33 \%$, the probability of transferring from silty mudstone (blue-gray) to coarse-grained sandstone (gray-white) is $33 \%$, the probability of transferring from silty mudstone (blue-gray) to 
coarse-grained sandstone (gray, grayish white) is $33 \%$. They have the same transition probability. Therefore, it can be seen that the organic matter is not oxidized and the uranium signal reaches the normal background value.

\section{Discussion}

In the two-time transition probabilities, the probability of transferring from carbonaceous mudstone (grayish black) to carbonaceous mudstone (grayish black) is 43.9\%. There are usually accompanying elements such as molybdenum, selenium, vanadium, plumbum in the sandstone-type uranium deposits. For the radioactive elements such as uranium and thorium contained in the grayish green and grayish-black lithic feldspar sandstone, there is data show that the content of uranium in the grayishgreen sandstones is significantly lower than that in the grayish-black sandstones. The average uranium content in the former is $3.38 \times 10^{-6}$, while in the latter this number is $14.33 \times 10^{-6}$. In the two kinds of sandstones, the content of thorium varies little, therefore, for the thorium/uranium ratio, the former is larger, with an average ratio of 1.78 , and the latter is smaller, with an average ratio of 0.31 . The uranium content, thorium content and strontium/uranium ratio in the grayish-green sandstone indicate that uranium has obvious outward migration, which also indicates that the grayish-green sandstones were subject to strong oxidation. Molybdenum and vanadium often comigrate with uranium during oxidation and precipitate and enrich in a reducing environment. It can be seen from the transition probability and the variation trend that the probability of transferring from carbonaceous mudstone (grayish black) to silty mudstone (blue-grey) is 33\%, and grayish-black carbonaceous mudstones have higher yttrium, zirconium and niobium contents than blue-grey silty mudstones, and the enrichment of these alkaline elements is due to the introduction of alkaline fluids. The geochemical characteristics of trace elements in grayish-black sandstones also indicate that they experienced a slightly acidic oxidation at an earlier time, and then were subject to the alkaline chloritization alteration. In view of the two giant uranium mineralization belts in the world, Russia attaches great importance to and pays close attention to the search of uranium mineralization resources, and applies the most commonly used geological distribution rules to search. In this paper, Markov process model is applied to analyze the sedimentary sequence and evolution relationship of the basin by means of transfer probability, which is of great importance to the distribution law of sand-salt uranium ore.

\section{Conclusion}

The study area of this paper is the northern margin of the Ordos Basin. Through the derivation of the Markov one-time transition and two-time transition probabilities, it can be seen that the black organic veins in the target sandstone layer of the study area have the mixed sources of coal-generated gas and oil gas, which also indicates that a strong oil-gas effect occurred after the formation of the sandstones. Studies have shown that there are also good conditions for oil and gas traps in the northern part of the Ordos Basin. The oil and gas fluids are generally alkaline and have a strong reduction effect; high-valent iron is reduced to low-valent iron, under such reductive and alkaline fluid conditions, the indication significance of the grayish-green sandstone for the uranium mineralization are well known, and the grayish-green sandstone indicates the reductive 
geochemical environment. After recognizing that it is a product of ancient oxidation and re-reduction, we can realize the essence through the appearance. In the northern part of the Ordos Basin, the grayish-green sandstones indicate a strong ancient oxidation effect, that is, a strong inter-layer oxidized uranium mineralization effect had occurred. The contact position between the grayish-black sandstones and the grayish-green sandstones, namely the pinch-out of the front of the ancient inter-layer oxidation zone, is the most favorable position for uranium mineralization. The obvious changes of sedimentary rhythm or sedimentary microfacies of river sand bodies, the transition zone of grayish-black sandstones and grayish-green sandstones, and the abnormal diffusion halo of uranium are caused by the different formation causes of the upper and lower sub-sections of the Zhiluo Formation, which resulted in significant differences in the sand body, structure and scale. The lower sub-section sand body has a larger scale and better connectivity, while the upper sub-section sand body has a smaller scale and a stronger heterogeneity. This law has an important guiding effect in understanding the expansion of sandstone uranium mineralization in the northern Ordos Basin, and it has important practical guiding significance for the exploration of similar deposits, especially sandstone uranium deposits in basins with rich oil, gas or coal resources. With the continuous development and progress of prospecting and exploration technology in the future, a variety of high-tech analytical and testing technologies can be applied to predict and evaluate the rules of uranium diagenesis and mineralization.

Acknowledgement. This paper was assisted by "evaluation of uranium resource potential based on big data", project No.2015CB453005 of project 973 "continental basin sedimentary environment and largescale mineralization in the giant sandstone uranium mineralization belt in northern China", project No. 2015 CB453000.

\section{REFERENCES}

[1] Adler, H. H. (1974): Concepts of uranium ore formation in reducing environments in sandstones and other sediments. - Formation of Uranium Ore Deposits 7: 141-168.

[2] Brookins, D. G. (1976): Position of uraninite and/or coffinite accumulations to the hematite-pyrite interface in sandstone-type deposits. - Economic Geology 5: 944-948.

[3] Chen, D. S., Li, S. X. (2003): A discussion on research situation and development direction of and stone-type uranium deposits in the meso-cenozoic basin of China. - Acta Sedimentologica Sinica 1: 113-117.

[4] Chen, Z. Z., Xiang, W. D. (2000): Uranium provinces in China. - Acta Geologica Sinica (3): 587-594.

[5] Cohenour, R. E. (1960): Geology and Uranium Occurrences near Lakeview. - Atomic Energy Comm., RME-2070, Oregon, US.

[6] Elmansour, A. A., Elseed, E. G. (2018): Groundwater dynamics in Ennuhud Basin, Kordofan Region, Sudan. - Environmental and Earth Sciences Research Journal 5(4): 94100.

[7] Fu, X. G., Tang, Z. H., Lv, W. B., Wang, X. M., Yan, B. Z. (2018): Exploitation potential of groundwater in Yangzhuang Basin, China under recharge enhancement. - International Journal of Heat and Technology 36(2): 483-493.

[8] Glass, L., Mackey, M. C. (1989): From Clocks to Chaos: The Rhythms of Life. Princeton University Press, Princeton, pp. 72-80. 
[9] Jin, R. S., Deng, J. (2015): Sedimentary environment and large-scale mineralization in continental basin of giant sandstone uranium metallogenic belt in north China. - World Nuclear Geology 5: 79-84.

[10] Lin, T., Luo, J. L., Liu, X., H., Zhang, S. (2007): Characteristics and genesis of sandstone type uranium inclusions in Zhiluo formation. - Acta Petrolei Sinica 5: 72-78.

[11] Liu, Y. Q., Feng, Q., Yang, R. C. (2006): Genesis of sandstone-type uranium deposits in Dongsheng area of Ordos Basin. - Geological Journal (5): 761-769.

[12] Martell, M. I. (2013): Introduction to discrete dynamical systems and chaos. - John Wiley \& Sons 5: 205-210.

[13] Mather, J. D. (2014): The Geochemistry of boron and its isotopes in groundwaters from marine and non-marine sandstone aquifers. - Applied Geochemistry 16: 821-834.

[14] Miao, A. S., Jiao, Y. Q. (2016): Fine anatomy of interlayer oxidation zone of Dongsheng uranium deposit in the northeast of Ordos Basin. - Frontiers of Geology 3: 55-61.

[15] Mclennan, S. M., Talyor, S. R. (2012): Sedimentary rocks and crustal evolution. Tectonic Setting and Secular Trend 99: 1-5.

[16] Wang, J. L., Zhang, J. H. (2019): Guided by the integration and innovation of Chinese uranium mineralization theories. Innovation and practice of management mode of geoscience and technology. - Geological Review 3: 772-773.

[17] Wyborn, L. A. I., Gallagher, R., Mernagh, T. P. (1995): Using GIS for mineral potential evaluation in areas with few known mineral occurrences. - Proceedings of the Second National Forum on GIS in the Geosciences. Australian Geological Survey Organisation Record 46: 6-24.

[18] Zhang, C. J., Chen, Y. L. (2010): Discovery and genetic significance of vertical Zoning of uranium deposits at 510-1. - Geology and Exploration 3: 434-441.

[19] Zhang, Z. L., Han, Y. Z. (2008): Geochemical characteristics and uranium mineralization in Zhiluo formation of Ordos Basin. - World Nuclear Geology 2: 79-84.

[20] Zhang, Z. L., Li, S. X. (2010): Lower member sedimentary facies of middle Jurassic Zhiluo formation in northeastern Ordos Basin and its control on uranium mineralization. - Acta Palaeogeography 6: 749-758. 